\title{
Video Presentation
}

\section{Situating Indigenous and Black Resistance in the Global Movement Assemblage}

\author{
GLEN COULTHARD \\ Yellowknives Dene \\ University of British Columbia, Canada \\ LEANNE BETASAMOSAKE SIMPSON \\ Michi Saagiig Nishnaabeg scholar \\ RINALDO WALCOTT \\ University of Toronto, Canada
}

"Situating Indigenous and Black Resistance in the Global Movement Assemblage" includes Glen Coulthard's keynote address at the Global Movement Assemblages symposium along with a panel exchange with Renaldo Walcott and Leanne Betasamosake Simpson. Coulthard presents the idea of a global assemblage of anti-imperialist radicalism, connecting Indigenous resistance and resurgence to the radical Black tradition. He recounts the $20^{\text {th }}$ century history of political alliance-building between Dene leaders and Africian anti-colonial movements, informed by "grounded normativity": ethics based on a relational ontology of deep reciprocity between people and place, and including non-human life forms. This is followed by presentations by Michi Saagiig Nishnaabeg scholar Leanne Betasamosake Simpson and Black Studies scholar Rinaldo Walcott speaking about Idle No More and Black Lives Matter respectively, with Yellowknives Dene scholar Glen Coulthard responding to them both. Simpson and Walcott each situate these movements within longer histories of struggle for freedom and being, and address translocal connectivities, but notably without using the language of assemblage. Each for their own reasons rejects assemblage thinking in favour of forms of critical thought arising from histories of resistance with which they are identified: the radical Black tradition for Walcott and Nissnaabeg intelligence and Indigenous resurgence more 
generally for Simpson. Simpson offers a compelling alternative to assemblage in the image of "constellations of co-resistance."

The video may be downloaded from:

http://hdl.handle.net/10464/13529

or viewed on YouTube at:

https://www.youtube.com/watch?v=vfuBOA_Yqzg 